\title{
Difference-in-Differences as a Tool \\ for Ex-Post Analysis of Mergers: The Case of a Merger in the Romanian Retail Market
}

\author{
Radu A. Păun and Danusia Vamvu
}

\section{Introduction}

This paper provides a broad overview of the analysis conducted by the Romanian Competition Council in the second half of 2013, following the authorization of a merger in the retail sector at the end of 2010. The implementation of the differencein-difference methodology (henceforth DiD) represented the core of this analysis, and this is what this paper will focus on.

Following a brief introduction to the subject matter, Sect. 2 describes the DiD technique, both graphically and mathematically (i.e. the general regression model applied to the data). Section 3 discusses the main hypotheses that the DiD rests upon and presents some further details about the decisions we had to make when conducting this analysis, primarily due to the merger characteristics and data availability. Section 4 presents the main results, along with some comments, while Sect. 5 concludes the paper.

The importance of the ex-post assessment of a merger decision stems from its main objective, which is to evaluate whether the aims of the decisions of the competition authority were reached or not. It is essential (but not sufficient) that a competition authority can verify if a decision has achieved the goal that justifies the existence of the merger control policy. However, this is not sufficient, given that, in order to minimize the number of inappropriate decisions in regards to merger control, the competition authority needs to also understand the reasons underpinning the failure or success, with respect to reaching the goals of the decisions.

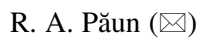

Industry and Energy Department, The Romanian Competition Council, Bucharest, Romania e-mail: radu.paun@competition.ro

D. Vamvu

Research Department, The Romanian Competition Council, Bucharest, Romania e-mail: danusia.vamvu@ competition.ro 
Experience has shown there is not one specific way to evaluate the effects of a merger clearance, and this is mainly due to the fact that authorising mergers requires the prediction of the merging firms' future conduct, which most certainly complicates the analysis and gives relative importance to the industry's structure and performance during the merger process. According to Weinberg (2008), there are three main approaches that have been used to measure the effects of mergers on prices: case studies, merger simulations, and direct comparisons of prices before and after the process of concentration. Whereas the first two approaches rely on assumptions that have a vital impact on the outcome of the analysis, before and after comparisons of prices offer a much more flexible and reliable framework for analysis.

According to Buccirossi et al. (2006), in regards to the ex-post analysis of a merger decision, it is important to fully grasp the aim of such analysis, but a consensus on what should be the economic objective of the merger control has not yet been reached. The opinions of the competition economists are divided between those who think that all antitrust interventions should be aimed at maximising consumer welfare and those who believe that total welfare should be the standard. However, the European Commission clears mergers only if they are not likely to negatively affect final consumers.

The importance of assessing merger clearances in the retail sector is twofold. Firstly, it stems from the highly concentrated retail sectors, which are becoming even more concentrated due to merger waves occurring throughout European countries since the 1980s. ${ }^{1}$ Secondly, supermarket mergers are a particularly important issue for antitrust authorities because food expenditures represent a large share of household budget (about 12.3\%, on average, in European countries in 2015) and $6.7 \%$ of the GDP. ${ }^{2}$

Therefore, in 2013 the Romanian Competition Council tried to assess whether the effects of a particular merger that it cleared in 2010 were positive on consumers or not. A significant part of this assessment was the implementation of the DiD methodology. Authors such as Ashenfelter and Hosken (2010) and Aguzzoni et al. (2011) argue that $\mathrm{DiD}$ is the most suitable ex-post impact assessment methodology of a merger decision.

Simply put, for a specific merger case in the Romanian retailer market, this paper tries to answer the following question: has the decision under examination (i.e. clearance of the merger) protected consumer welfare, or would this goal have been better achieved had the Romanian Competition Authority adopted a different decision (e.g. to block the merger or to conditionally approve it)? In other words, we are set to find the best way to isolate, estimate and assess the effects of the cleared

\footnotetext{
${ }^{1}$ According to Allain et al. (2015), in 2004, $\mathrm{CR}_{3}$ was $91.2 \%$ in Denmark, $79.6 \%$ in Finland, $81 \%$ in Iceland, $82 \%$ in Norway, and $91.2 \%$ in Sweden, while in $2003, \mathrm{CR}_{5}$ was $72.6 \%$ in France, $67.8 \%$ in Germany, $69.1 \%$ in Spain, $68.5 \%$ in Portugal and $63.5 \%$ in the UK. Furthermore, among the 100 retail mergers requests presented to the European Commission between 1990 and 2012, 89 were approved, 8 were approved subject to conditions, and only 3 were denied.

${ }^{2}$ http://ec.europa.eu/eurostat/statistics-explained/index.php/Household_consumption_by_purpose
} 
merger on prices of the offered goods and see whether this was beneficial or harmful to end consumers.

As Jiménez and Perdiguero (2012) point out, the number of papers using the DiD approach to analyse the effects of mergers has grown in recent years. According to these authors, most of the studies using this methodology concluded that prices increased as a result of the merger (they also provide several examples of studies reporting significant price hikes). In their particular case, Jiménez and Perdiguero (2012) use evidence from an exogenous merger between two retail gasoline companies in a specific market in Spain and conclude that the concentration did not lead to price increases. By contrast, Connor et al. (1988) found cost and price reductions after a merger between US hospitals. In rail transport, Karikari et al. (2002) also noted reductions in prices, although this result depends on the type of goods, direction of traffic, and the type of transport.

In regards to retail merger analyses, Allain et al. (2015) assess the impact of a merger in the French supermarket industry on food prices and, by performing a DiD analysis on consumer panel data, they concluded that the merging firms significantly raised their prices after the merger, but nationally rather than locally. The increase of the competitors' prices was stronger in local markets where more merging firms operated and in which differentiation changed following the merger.

To conclude, empirical merger analysis of the retail sector seems to go in two main directions, with lively debates between the two approaches: on the one hand, some papers build structural models of demand and supply in order to simulate merger effects using pre-merger data, ${ }^{3}$ whereas, on the other hand, some papers use both pre- and post-merger data on prices to directly estimate the effects of the structural changes and mergers. ${ }^{4}$ The latter is the one we took in our analysis.

\section{The Difference-in-Differences Technique}

The main problem in trying to analyze the ex-post behaviour of the parties involved in a horizontal merger, by determining the effect of the merger on prices, lies in choosing an appropriate method that can control for all other factors that could influence prices. We are referring here primarily to the effects of any changes that may occur on the demand or the supply side (e.g. consumer preferences, income, cost level, taxation, etc.).

We chose the DiD methodology because it seems to be the best practice in assessing ex-post merger impact, it is often used by competition authorities such as the US Federal Trade Commission and the UK Competition and Markets

\footnotetext{
${ }^{3}$ For example, Smith (2004) simulated structural changes in the UK supermarket industry and found that retail divestitures reduced prices while mergers increased prices.

${ }^{4}$ The most relevant to our case are Ashenfelter and Hosken (2010), Ashenfelter et al. (2013), and Ashenfelter et al. (2015).
} 


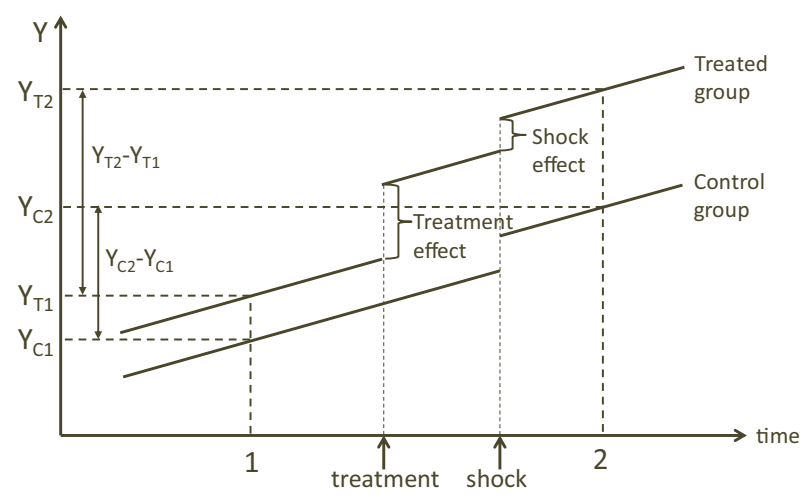

Fig. 1 Choosing a representative control group

Authority, and is also recommended by consultants such as LEAR and Compass Lexecon. This technique greatly depends on selecting a representative control group, as well as choosing a suitable time window around the event (in our case, the cleared merger).

Using terminology that comes from medical studies, DiD involves the comparison of two groups of individuals: the treatment group and the control group. ${ }^{5}$ In our case, "the treatment" refers to the takeover by retailer A of all the stores of retailer B.

A "before and after" analysis is limited in the sense that it only works if the trends of the treatment and control groups are parallel and if there are no shocks affecting the treatment group differently than the control group. In order to show this, we depicted the estimated effect and the real effect of the merger when choosing a reliable control group (Fig. 1) and an inappropriate control group (Fig. 2).

In general, in merger control one may look at the merger's impact on product prices, quantities, product quality, or range. In Fig. 1, any one of these variables is denoted by $\mathrm{Y}$ and is plotted on the vertical axis, whereas time is plotted on the horizontal axis.

In brief, the control group is meant to display the "normal" evolution of the phenomenon (e.g. product price, quantity, quality, or range) over time, both before and after the treatment (in our case, the merger). Apart from trend parallelism, this also implies that the control group is exposed to all the shocks that also impact the treatment group (and with the same magnitude). The only difference between the control and the treatment groups is the fact that the latter is also affected by the treatment (merger) under investigation. This means that the difference in time and across the two groups (i.e. the difference of the differences) will isolate the treatment effect.

\footnotetext{
${ }^{5}$ The treated group refers to those stores that are "treated" (the stores from the five potentially problematic areas in regard to the merger), whereas the control group "gets the placebo" (those stores not affected by the merger).
} 
Fig. 2 An example of an inappropriate control group

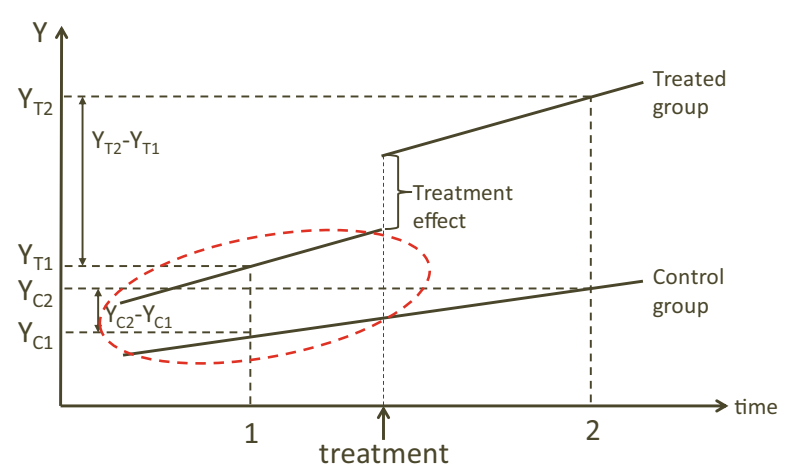

Table 1 Mathematically formulated difference-in-differences technique

\begin{tabular}{l|l|l|l}
\hline & Before the merger & After the merger & Difference \\
\hline Treatment group & $P_{1,1}$ & $P_{1,2}$ & $\Delta P_{1}=P_{1,2}-P_{1,1}$ \\
\hline Control group & $P_{2,1}$ & $P_{2,2}$ & $\Delta P_{2}=P_{2,2}-P_{2,1}$ \\
\hline & & $\Delta \Delta P=\Delta P_{2}-\Delta P_{1}$ \\
\hline
\end{tabular}

It is apparent that when the trends of the treatment and control groups are not parallel, even in the absence of additional shocks, the estimated effect would be misleading (the difference of the two trends contaminates the estimated treatment effect). This is just one example of an inappropriate control group. Another could be a control group which is exposed to different shocks than the treatment group, or to the same socks, but with a different magnitude.

In our particular merger case, given the available data, we analyze the behaviour of the merger parties before and after the merger, in those locations that are potentially problematic due to the suspected opportunity to increase prices following the strengthening of market shares over a certain critical threshold.

More specifically, we are interested in the price dynamics of the involved parties in those areas that are identified as potentially problematic in comparison to prices from other stores, belonging to the same retailer, but in areas that are not affected by the merger. Consequently, in what follows, the variable formerly denoted by $\mathrm{Y}$ is replaced by $\mathrm{P}$ (Table 1 ).

The above table shows that for each product that we are interested in, we first calculate the difference between prices from the "before" and "after" periods, for the treatment and control groups $\left(\Delta P_{1}\right.$ and $\Delta P_{2}$, respectively), and then the difference between these differences $(\Delta \Delta P)$.

As indicated above, if the control group is correctly chosen so that its evolution is similar to that of the treatment group before the merger, and it is exposed to the same shocks (and with the same magnitude) as the treatment group, it can be reasonably assumed that the evolution of the control group observed throughout the post-merger period represents the "normal" evolution of the market. As a result, the difference between the differences isolates solely the treatment effect (the effect of the approved merger) on the treatment group. 
Table 2 Econometrically formulated difference-in-differences technique

\begin{tabular}{l|l|l|l}
\hline & Before the merger & After the merger & Difference \\
\hline Treatment group & $P_{1,1}=\beta_{0}+\beta_{1}$ & $P_{1,2}=\beta_{0}+\beta_{1}+\beta_{2}+\beta_{3}$ & $\Delta P_{1}=\beta_{2}+\beta_{3}$ \\
\hline Control group & $P_{2,1}=\beta_{0}$ & $P_{2,2}=\beta_{0}+\beta_{2}$ & $\Delta P_{2}=\beta_{2}$ \\
\hline
\end{tabular}

The DiD analysis can also be achieved by estimating a regression model that is formulated as:

$$
P_{i, t}=\beta_{0}+\beta_{1} \cdot \text { Treated }_{i}+\beta_{2} \cdot \text { Post }_{t}+\beta_{3} \cdot \text { Treated }_{i} \cdot \text { Post }_{t}+\varepsilon_{i, t}
$$

where $i$ represents the store, $t$ is the time period (week, month, quarter, given case features), Treated is a dummy variable whose value is 1 if the store is part of the treatment group, 0 otherwise, Post is a dummy variable whose value is 1 for the postmerger period, 0 otherwise. The last term of the model represents the interaction between the two dummy variables described above, thus taking value 1 if the data corresponds to a store from the treatment group in the post-merger period.

Given the way the variables are defined in the regression model, the estimated coefficients are used directly in the DiD analysis, as shown in Table 2.

Therefore, the $\beta_{3}$ coefficient indicates exactly the impact of the treatment (the impact of the merger) on product prices and is thus what we are specifically interested in.

The main advantage of using the regression model for the DiD analysis is that it allows further investigation of the statistical significance of the estimated coefficient $\beta_{3}$, thus avoiding misinterpretation of the results. ${ }^{6}$

Another advantage, inherent to the regression analysis, is that $\beta_{3}$ will capture the average treatment effect, as it is estimated using data over two periods of time, before and after the merger, not just the two particular moments in time, denoted as 1 and 2 in the figures above. Consequently, the results obtained through the regression analysis are considered to be more meaningful than the punctual effect (which may depend on data particularities, mismeasurement, etc.).

Given the way that model (1) is specified, $\beta_{3}$ is also the average treatment effect across all stores in the treatment group (see discussion below).

The model presented in Eq. (1) can be extended by adding other variables that could explain the average price dynamics during the analysed time frames, thus obtaining more reliable results (i.e. avoiding the omitted variables bias). At the same time, the model extension can also be justified by imperfections of the control group: the addition of the right explanatory variables will allow slight differences between the treatment and the control groups, and will thus improve the estimate of the $\beta_{3}$ coefficient.

\footnotetext{
${ }^{6}$ While a result obtained using the tabular version of the DiD technique can still be representative, it might not be statistically significantly different from zero.
} 
One example of an explanatory variable that may be added to the model is product quality, as changes in quality over time may lead to price changes and the effect may be different in the two groups. As indicated further, adding product quality into the model was not necessary in our particular case. ${ }^{7}$

Another example is the addition to the regression model of time dummies. By introducing time-fixed effects, one could account for seasonal changes of different magnitude in the two groups. Hence, an extended version of model (1) can have the form expressed in Eq. (2):

$$
P_{i, t}=\beta_{0}+\beta_{1} \cdot \text { Treated }_{i}+\beta_{2} \cdot \text { Post }_{t}+\beta_{3} \cdot \text { Treated }_{i} \cdot \text { Post }_{t}+\beta_{4} \cdot \text { Time }+\varepsilon_{i, t}
$$

where Time is a vector of dummy variables, representing weeks, months, quarters, etc. ${ }^{8}$ In most cases, the Time variable will probably represent the months of the year, hence this vector will comprise 11 dummies, one for each month. ${ }^{9}$

The model above could be further expanded by adding store-fixed effects (i.e. store dummy variables). This would allow for the intercept of the regression to vary across stores, and would attenuate possibly omitted variables bias, provided that the omitted variables are store-invariant (this is similar to adding time-fixed effects, the case in which the possibly omitted variables would need to be timeinvariant).

Last but not least, a natural logarithm transformation could be applied to price data, so that the coefficient of interest $\left(\beta_{3}\right)$ can be directly interpreted as the percentage change in product price following the merger clearance.

When fitting model (2) to data, the $\beta_{3}$ estimate will capture the impact of the cleared merger on prices for the treatment group as a whole. Adding time- and/or store-fixed effects into the model will allow variation of the intercept by time and/or store, but $\beta_{3}$ will still indicate the average treatment effect (average over time and for all stores in the treatment group). ${ }^{10}$

In our particular case, we decided to introduce into the regression model a dummy variable for each month of the year (hence subscript $t$ also represents a month) and to use price data in logarithm (for ease of result interpretation). Then, we ran a regression similar to model (2), separately, by product and for each store in the treatment group. This means that the $\beta_{3}$ coefficient of each regression indicates the

\footnotetext{
${ }^{7}$ This is fortunate because capturing product quality, especially in numerical form, in order to include it in a regression model, can prove to be an extremely difficult task. To collect such information, one may need to rely on consumer perception through carefully designed questionnaires.

${ }^{8}$ This choice should take into consideration case characteristics and should match the choice of $t$. ${ }^{9}$ One month needs to be omitted to avoid the resulting multicoliniarity, due to the fact that the regression model contains an intercept, $\beta_{0}$ which captures the impact of the omitted month on prices.

${ }^{10}$ Unless the time and/or store dummies are not interacted with the other variables in the regression model.
} 
impact on product price in that particular store, part of the treatment group, relative to all stores in the control group.

As indicated in Sect. 3, we focused on 11 food product categories and the treatment group consist of five potentially problematic stores. Consequently, we ran 55 different regressions, thus the results presented in Sect. 4 comprise 55 different $\beta_{3}$ estimates.

\section{Applying the Methodology: Main Assumptions and Decisions}

In general, the $\mathrm{DiD}$ methodology may be used to compare prices (or other metric) of the products offered by the merger parties (the treatment group) to those offered by similar competitors (the control group), during two different time intervals, before and after the merger clearance. As indicated previously, if the control group is appropriately chosen (displays a trend similar to that of the treatment group and is exposed to the same shocks), this approach will isolate the effect of the merger over the parameter of interest (usually the price).

However, comparing the price evolution of the products offered by the merger parties with those offered by similar competitors might lead to a major problem: a false negative result. This is the case when the merging parties are influential enough that they might increase the price for their products and other players would follow suit. In this scenario, a DiD analysis may show no significant increase in relative prices between treatment and control groups only because they increased in a similar way. In a retail case, an approach that eliminates the threat of false negatives would be to compare the price of products offered by different stores from the same chain before and after the merger.

The first assumption we made is that, in what follows, all companies active in the retail sector (whether hypermarkets, supermarkets, or any other type of stores) provide products to consumers (predominantly individuals). This makes things easier for us since it means that the prices that we consider in the analysis are the shelf prices for the selected products.

An alternative view is that companies active in the retail sector provide a shelf listing service for various products, with the customers of this service being mostly legal entities (manufacturers or intermediaries for the listed products). Therefore, in this scenario, the analysis should take into account the listing price for the shelf products.

As mentioned above, the analysis that we use in this paper involves a comparison of price levels during two symmetrical time intervals, before and after the merger. The time periods analysed must be sufficiently long to allow for the full manifestation of the effects of the merger, and short enough to avoid any contamination effects from other changes that may occur in the market following the merger and which might manifest differently in the treatment and control groups, thus affecting the 
comparability of the two groups (e.g. the appropriateness of the control group). Some authors consider ideal to look at a 3-year interval starting from the date of the merger ( 2 years if the market is highly dynamic and innovative), while others use symmetric time intervals of 1 year each, before and after the merger, excluding from the analysis 1 year around the merger.

Another methodological aspect that should be emphasised refers to the actual nature of the analysed merger. More specifically, the papers that deal with ex-post merger assessment generally focus on two companies, call them A and B, which operated independently prior to the merger and as one following the merger, e.g. in the form of company $\mathrm{AB}$. In our case, however, a retailer who was not present in contemporary retail market (Lidl) entered this market through the complete acquisition of another retailer (Plus). This means that, prior to the merger, we have data regarding the activity of Plus, whereas, after the merger, we have data regarding the activity of Lidl.

Even though the two brands operate in the same market segment of the retail sector (hard discounters), there are significant differences between them (in terms of commercial policy, product range, quality, etc.). Furthermore, consumer perception of the two brands is likely to be different, given, for example, the resources invested by the two companies in communication and marketing activities. This means that a price comparison between the two retailers is very sensitive and should be treated with caution.

This issue led us to look at the conduct before and after the merger of another retailer, Kaufland, which is part of Schwarz Gruppe, along with Lidl, and which could see the takeover of Plus by Lidl as an opportunity to raise prices, particularly in those areas where the position of the group was strengthened following the merger. This aspect becomes extremely important when discussing the appropriate choice of the control and treatment groups.

The merger analysis included the DiD assessment presented in this paper, but also the analysis of market evolution in some areas, the review of entries in the retail market and their development, the analysis of private labels and the analysis of the procurement market, all of which were performed within the Romanian Competition Council, by the Consumer Goods Department (while the DiD analysis was assigned to the competition authority's Research Department).

The first decision we had to make refers to the parameter (or parameters) that were to be analysed through the DiD. Even though, conceptually, one may look at different aspects that may be affected by the merger, such as product price, quantity, quality, or range, for obvious reasons most ex-post studies focus on merger impact on product prices. Consequently, our ex-post analysis of the Lidl-Plus merger focused also on prices.

The second decision refers to the definition of the control and treatment groups. As indicated above, comparing Plus prices before the merger to Lidl prices following the merger was not seen as an option, and we decided to analyse Kaufland prices instead. Discussions within the Competition Council showed the need to analyze the 


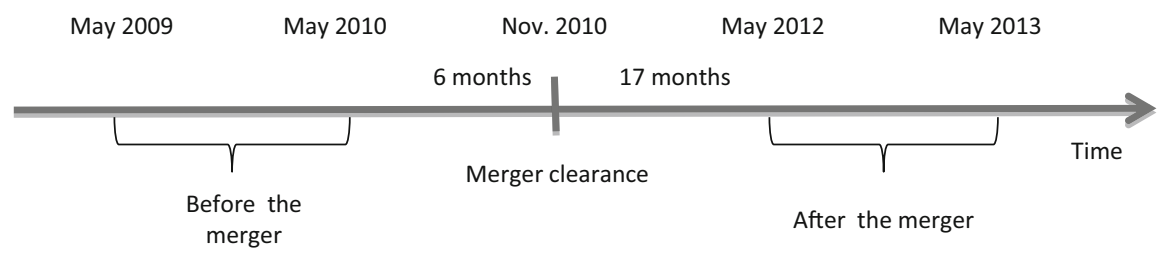

Fig. 3 The time intervals used in the ex-post merger analysis

existing situation in five potentially problematic Kaufland locations ${ }^{11}$ where the Schwarz Gruppe's position strengthened significantly following the takeover of retailer Plus by Lidl. Hence, the treatment group consists of five Kaufland stores. The control group is made of 11 other Kaufland stores, located in areas unaffected by the merger (i.e. areas where Plus stores were not present, or their presence was limited) and in cities of similar size to those from the treatment group. ${ }^{12}$

The third decision was related to the products that would be included in the analysis. We focused on 11 basic food product categories such as milk (regardless of fat content, the form of packaging, brand, pasteurization level etc., in order to compute the average price/litre), meat and sausage products (regardless of the form of packaging, brand, product type, in order to compute the average price $/ \mathrm{kg}$ ), non-alcoholic beverages (average price/litre), bread, tomatoes. The complete list of the product categories included in our analysis is given in Table 3 . The analysis could have included non-food items and be dealt with them in a similar manner, so long as the selected categories are offered by both the treatment and control group.

The fourth decision we had to make referred to the time dimension of the analysis (Fig. 3). In this respect, given various restrictions, we ended up with the following two periods: May 2009-May 2010 (the "before" period), and May 2012-May 2013 (the "after" period). The time horizon covered by the data is somewhat narrower than ideal, covering two symmetrical periods of 13 months each. However, we do not believe that the $\mathrm{DiD}$ analysis was affected significantly, the only question that arose referred to the time window between the approval of the merger (November 2010) and the first moment following the merger for which we had available data (May 2012), which may be seen as slightly too wide.

In our view, it is essential that the "before" and "after" time intervals are similar in the sense that they contain the same months of the year, in order to isolate the seasonal price fluctuation. Additionally, by eliminating the time interval around the date of the merger (November 2010), we avoid the problem of the period in which firms begin coordinating their behaviour (through pricing), so that leaves us with only those periods underlying the uncontaminated prices, for both "before" and "after" time intervals. Finally, we assume that there were no significant changes in the market structure that would have altered the behaviour of the retailer after the merger

\footnotetext{
${ }^{11}$ Due to confidentiality issues, the five potentially problematic stores are referred to as $\mathrm{K} 1, \mathrm{~K} 2, \mathrm{~K} 3$, K4 and K5. Each of these Kaufland stores is located in a different town of Romania, with a population of between 50,000 and 85,000 .

${ }^{12}$ For example, this means that no Kaufland store in Bucharest is part of the control group.
} 
differently between the two groups, thus assuming that the two symmetrical periods before and after the merger are still comparable for the control and treatment groups.

Before going over the results of our analysis, we need to stress one particular aspect. Kaufland stores in Romania carry mostly the same range of products across the network, especially in the food department. As a result, by having only Kaufland stores in both the treatment and the control groups, we eliminate the possibility of different changes in product range or quality between the treatment and the control groups, as a result of the merger. In other words, if Kaufland made a change in the product range or the quality for the 11 product categories we monitored, for example by introducing private labels into Kaufland's offer, it made the same adjustment at all stores in its network. Consequently, the main parameter of interest for this ex-post analysis remains the product price.

\section{Results}

If Eq. (2) is fitted to price data for one particular product of interest, it returns one estimated $\beta_{3}$ coefficient, which would indicate the average effect on prices that the merger had for all stores in the treatment group, relative to the stores in the control group, for the two considered time periods.

Instead of adopting this approach, which would have implied running 11 OLS regressions (one for each product category we have chosen), we decided to run separate regressions for each of the five potentially problematic Kaufland stores in the treatment group and for each of the 11 product categories. By doing so, we allow for the estimated coefficients to differ from one regression to another, hence for the merger impact on prices to vary across the Kaufland stores in the treatment group. In other words, we have not estimated the average merger impact on prices for the treatment group as a whole, but rather the merger impact on prices at the store level. The coefficient of interest is still $\beta_{3}$ and represents the percentage change in the price of the product, due to the merger clearance.

Our decision has led to 55 separate regressions. Each of these regressions relies on 260-273 observations, with the exception of the five regressions related to fresh bread-this product was included in Kaufland's offer at the end of 2009, leading to a somewhat smaller dataset of $210-216$ data points. $\mathrm{R}^{2}$ adjusted for degrees of freedom (14) is above 0.6 in all regressions, except for those associated to cold cuts, where it ranges from 0.3 to 0.43 , depending on the Kaufland store in the treatment group. For all regressions considered, the $F$-test of overall significance shows that the proposed regression models fit the data well (all $p$-values are virtually zero).

The coefficient of interest remains $\beta_{3}$ and represents the percentage change in the price of product category due to the merger clearance. Table 3 summarises the results.

Before running each individual regression, we visually inspected the price trends in the control and treatment groups before the merger, and identified six cases where trends were significantly different. For these six cases, which match the situation depicted in Fig. 2, the DiD analysis is not applicable. Consequently, these cases were marked by $\mathrm{X}$ in Table 3 . 
Table 3 Results using DiD

\begin{tabular}{l|l|l|l|l|l}
\hline & $\mathrm{K} 1$ & $\mathrm{~K} 2$ & $\mathrm{~K} 3$ & $\mathrm{~K} 4$ & $\mathrm{~K} 5$ \\
\hline Milk & $-2.23 \%$ & $-2.35 \%$ & $-2.16 \%$ & $-1.11 \%$ & $-6.53 \% * * *$ \\
\hline Apples & $+3.91 \%$ & $-1.45 \%$ & $+3.32 \%$ & $+0.76 \%$ & $-1.78 \%$ \\
\hline Cold cuts & $\mathrm{X}$ & $+2.04 \%$ & $+0.31 \%$ & $+3.11 \%$ & $\mathrm{X}$ \\
\hline Fresh bread & $\mathbf{- 0 . 5 0 \%}$ & $-\mathbf{1 . 3 6 \%}$ & $\mathbf{X}$ & $-\mathbf{0 . 0 9 \%}$ & $-\mathbf{5 . 9 4 \%} * * *$ \\
\hline Poultry & $-4.53 \% *$ & $-7.29 \% * * *$ & $+1.08 \%$ & $+0.57 \%$ & $-4.88 \% *$ \\
\hline Pork & $-5.70 \% * * *$ & $-4.99 \% * * *$ & $-5.50 \% * * *$ & $\mathrm{X}$ & $-3.81 \% * *$ \\
\hline Potatoes & $-2.62 \%$ & $+0.86 \%$ & $-3.96 \%$ & $-3.13 \%$ & $-5.38 \%$ \\
\hline Eggs & $+0.99 \%$ & $+5.95 \% *$ & $-5.18 \%$ & $+5.80 \% *$ & $-3.64 \%$ \\
\hline Tomatoes & $+0.80 \%$ & $-6.96 \% *$ & $+1.40 \%$ & $-1.89 \%$ & $-6.17 \%$ \\
\hline Sunflower oil & $+0.83 \%$ & $\mathrm{X}$ & $-0.93 \%$ & $+1.12 \%$ & $+0.84 \%$ \\
\hline Wine & $-4.25 \%$ & $\mathrm{X}$ & $-2.60 \%$ & $+11.47 \% * * *$ & $-2.22 \%$ \\
\hline
\end{tabular}

*The merger impact on price is statistically significant at $10 \%$

**The merger impact on price is statistically significant at $5 \%$

***The merger impact on price is statistically significant at $1 \%$

The results for the "fresh bread" category should be treated with caution because the product was included in Kaufland's offer only at the end of 2009, which means that the time intervals before and after the merger are not similar. The lack of data for this product category starting from May 2009 until November 2009 affects the $\beta_{4}$ coefficient estimates for these months, ultimately distorting the coefficient of interest, $\beta_{3}$.

In addition to the six cases marked by $\mathrm{X}$, Table 3 shows many price changes that are not statistically significantly different from zero (36 such cases). All in all, there are 31 price decreases following the merger and only 18 price increases. Moreover, taking into account only the estimates which are statistically significantly different from zero, there are ten such price decreases ( $20 \%$ of the 49 cases where the analysis could be performed under good conditions) and only three price increases (6\% of the 49 cases). In other words, it appears that the situations where, for a specific product category in a specific Kaufland store, the price decreased relative to the price in the control group following the merger outnumber the situations where the relative price increased.

Consequently, the broad image Table 3 projects is one of some benefits being passed on to the Kaufland customers following the Lidl-Plus merger, and not of a general increase in Kaufland prices following the merger clearance.

\section{Conclusions}

The economic analysis of mergers remains one of the most complex tasks in antitrust enforcement, especially because mergers can have opposing effects for consumers: on the one hand they could generate efficiency gains (translated into lower prices) 
while, on the other hand, the elimination of a competitor may lead to unilateral or coordinated effects.

The approach we adopted in assessing this particular retail merger clearance used the DiD methodology. Given the information available, the DiD analysis can be implemented for some Kaufland potentially problematic locations, by comparing price dynamics at these locations with those in the control group (11 other Kaufland stores in the country). This analysis tested the hypothesis that Kaufland could decide to increase prices of products sold at those locations where the resulting shares rose above a certain critical threshold on account of to the merger clearance. The results indicate only isolated price increases following the merger ( 3 out of 49 cases), these situations being clearly outnumbered by relative price decreases following the merger (10 out of 49 cases).

This paper fits into a growing literature which attempts to evaluate whether approved mergers actually led to increased prices. When assessing a particular case on the Romanian retail market, we concluded that the retail prices of 11 food product categories remained primarily unaffected by the merger. Moreover, there are more cases of price decreases following the merger than there are of price increases. Consequently, the Romanian Competition Council's decision to approve the merger can be considered correct (in this case, increased market concentration was not detrimental to consumers).

\section{References}

Aguzzoni L, Argentesi E, Buccirossi P, Ciari L, Duso T, Tognoni M, Vitale C (2011) The ex-post evaluation of two merger decisions, LEAR

Allain ML, Chambolle C, Turolla S, Villas-Boas SB (2015) The impact of retail mergers on food prices: evidence from France, Department of Agricultural \& Resource Economics, UC Berkeley, Working Paper Series

Ashenfelter O, Hosken D (2010) The effect of mergers on consumer prices: evidence from five mergers on the enforcement margin. J Law Econ 53(3):417-466

Ashenfelter O, Hosken D, Weinberg MC (2013) The price effects of a large merger of manufacturers: a case study of Maytag-Whirlpool. Am Econ J Econ Policy 5(1):239-261

Ashenfelter O, Hosken D, Weinberg MC (2015) Efficiencies brewed: pricing and consolidation in the US beer industry. RAND J Econ 46(2):328-361

Buccirossi P, Ciari L, Duso T, Fridolfsson SO, Spagnolo G, Vitale C (2006) Ex-post review of merger control decision, LEAR

Connor RA, Feldman RD, Dowd BE (1988) The effects of market concentration and horizontal mergers on hospital costs and prices. Int J Econ Bus 5:159-180

Jiménez JL, Perdiguero J (2012) Mergers and difference-in-difference estimator: why firms do not increase prices? Research Institute of Applied Economics, Working Paper 
Karikari JA, Brown S, Nadji M (2002) The Union Pacific/Southern Pacific railroads merger: effect of trackage rights on rates. J Regul Econ 22:271-285

Smith H (2004) Supermarket Choice and Supermarket Competition in Market Equilibrium. Rev Econ Stud 71(1):235-263

Weinberg M (2008) The price effects of horizontal mergers. J Compet Law Econ 4:433-447

Open Access This chapter is licensed under the terms of the Creative Commons Attribution 4.0 International License (http://creativecommons.org/licenses/by/4.0/), which permits use, sharing, adaptation, distribution and reproduction in any medium or format, as long as you give appropriate credit to the original author(s) and the source, provide a link to the Creative Commons license and indicate if changes were made.

The images or other third party material in this chapter are included in the chapter's Creative Commons license, unless indicated otherwise in a credit line to the material. If material is not included in the chapter's Creative Commons license and your intended use is not permitted by statutory regulation or exceeds the permitted use, you will need to obtain permission directly from the copyright holder. 